\title{
Penggunaan Remifentanil pada Pasien Pediatrik dengan Meningokel yang Dilakukan Tindakan Eksisi Meningokel
}

\author{
Kenanga M. Sikumbang*), Ardik Lahdimawan ${ }^{* *}$ \\ ${ }^{*}$ Divisi Neuroanestesi IPDS Anestesiologi dan Terapi Intensif Fakultas Kedokteran Universitas Lambung \\ Mangkurat-RSUD Ulin Banjarmasin, ${ }^{* *}$ Divisi Neurosurgery IPDS Ilmu Bedah Fakultas Kedokteran Universitas \\ Lambung Mangkurat - RSUD Ulin Banjarmasin
}

\begin{abstract}
Abstrak
Meningokel adalah kondisi kegagalan fusi selubung saraf medulla spinalis yang umum ditemui pada pasien pediatrik. Koreksi meningokel dilakukan dalam posisi prone yang memerlukan tatalaksana anestesi yang hati-hati. Fisiologi neonatus dan infant berbeda dengan orang dewasa, karena fungsi fisiologis system organ masih imatur dan menyebabkan safety margin terbatas, sehingga pilihan obat adalah yang metabolismenya tidak tergantung pada fungsi hati dan ginjal normal. Dalam bidang neuroanestesi pediatrik, penggunaan remifentanil semakin luas, karena onset cepat, efek analgesik poten dan eliminasi cepat. Seorang bayi laki-laki, usia 7 bulan dengan berat badan $7 \mathrm{~kg}$, diagnosis meningokel lumbosacral dilakukan tindakan eksisi meningokel. Pasien diberikan remifentanil $1 \mathrm{mcg} / \mathrm{kgbb}$ selama 1 menit dilanjutkan dengan remifentanil kontinyus $0.05-1 \mathrm{mcg} / \mathrm{kgbb} / \mathrm{mnt}$. Induksi dengan propofol, diberikan atracurium sebelum intubasi. Selama operasi kondisi stabil, tidak terjadi episode bradikardi dan pascaoperasi pasien langsung diekstubasi. Penggunaan remifentanil menjadi pilihan karena onset cepat, efek analgesik poten, eliminasi cepat dan memberikan stabilitas hemodinamik selama operasi. Operasi dengan posisi prone pada pasien pediatrik memerlukan kehati-hatian terutama saat memposisikan pasien, dimana harus yakin pipa ett tidak mengalami dislokasi atau kinking, mencegah efek penekanan pada mata dan pencegahan terjadinya neuropati perioperatif. Pemakaian remifentanil pada kasus ini memberikan stabilitas hemodinamik yang baik dan pulih sadar yang cepat.
\end{abstract}

Kata kunci: meningokel, pediatrik, posisi prone, remifentanil

JNI 2021; 10 (1): 40-6

\section{Using Remifentanyl For Pediatrik Patient With Meningocele Underwent Meningocelectomy Under General Anesthesia}

\begin{abstract}
Meningocele is failure of the neural tube to close during first trimester pregnancy which is the most common conditions in pediatrik patient. Correction is performed under prone position with carefull anesthestic procedure. The physiology of neonates and infants are different from that of adults. Immaturity of their vital organ systems narrows the safety margin of perioperative management including anesthesia. Remifentanil is becoming increasingly popular for this purpose. Remifentanil has favorable characteristics for anesthesia in neonates such as rapid onset, potent analgesic effect, and rapid elimination. A baby boy 7 months old, $7 \mathrm{~kg}$, with meningocele lumbosacral underwent meningocelectomy. The patient was given remifentanil $1 \mathrm{mcg} / \mathrm{kgbw} / \mathrm{iv}$ in one minute and continuous $0.05-0.1 \mathrm{mcg} / \mathrm{kgbw} / \mathrm{mnt}$. Induction with propofol iv, atracurium before intubation. Stability hemodynamic during the operation, no episode of bradycardia and patient extubated early after the operation. Remifentanil is an ultra-short-acting opioid, with rapid onset, produces profound analgesia, rapid offset and good stability of hemodynamic during the operation. The operations are carried out prone, careful positioning is paramount to avoid complications like dislodging or kinking of the endotracheal tube, corneal abrasion or perioperative neuropathy. Using remifentanyl in this case report given good hemodynamic stability dan rapid emergence.
\end{abstract}

Key words: meningocele, pediatrik, prone position, remifentanyl

JNI 2021,;10 (1): 40-6

This article is licensed under

Creative Commons Attribution-NonCommercial-ShareAlike 4.0 International License.

CKenanga M. Sikumbang, Ardik Lahdimawan

(2021) under the CC-BY-NC-SA license 


\section{Pendahuluan}

Pasien pediatrik dengan berbagai patologipenyakit pada medulla spinalis umumnya memerlukan operasi spinal. Penyakit yang paling umum adalah defek pada selubung saraf yang dikenal sebagai mielodisplasia akibat gagalnya fusi embriologi selubung saraf pada bulan pertama kehamilan. Angka kejadian mielodisplasia meliputi sekitar 1/1000 kelahiran. Kegagalan fusi selubung saraf ini menyebabkan terjadinya kondisi menyerupai hernia pada meningen (meningokel) dan herniasi disertai jaringan saraf (mielomeningokel). Mielomeningokel paling sering terjadi di area lumbosakral, tapi dapat terjadi di semua level tulang belakang dan jika terjadi di area torakal biasanya disertai gangguan neurologis yang berat. ${ }^{1,2}$ Eksisi dan menutup meningokel dilakukan dalam posisi prone dan biasanya tindakan ini menjadi tantangan tersendiri bagi tim operasi. Melakukan intubasi trakea dalam posisi supine dapat menyebabkan ruptur membran yang menutupi bagian medulla spinalis yang terpapar. Intubasi dalam posisi supine dapat dilakukan dengan aman dengan memberikan alas berbentuk donat atau padding berbentuk cincin pada area mielomeningokel. Pada kasus mielomeningokel yang besar, kadang dilakukan intubasi dengan posisi miring. ${ }^{3}$ Tujuan operasi spinal adalah untuk mengoreksi atau membatasi terjadinya gangguan neurologis. Tindakan anestesi pada operasi spinal pasien pediatrik harus ditujukan untuk keperluan posisi dan monitoring jika terjadi problem medis, patofisiologi terkait usia, potensi kehilangan darah dan gangguan vaskularisasi pada medulla

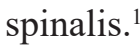

Fisiologi neonatus dan infant berbeda dengan orang dewasa dimana hal ini mempengaruhi pemilihan obat. Fungsi hati dan ginjal belum sepenuhnya berkembang saat lahir dan baru mengalami pematangan dalam beberapa bulan di tahun pertama kehidupan. Obat-obat yang dikembangkan dalam 10-20 tahun terakhir ini berfokus pada obat yang metabolismenya tidak tergantung pada fungsi hati dan ginjal normal, mengingat pada usia dewasa mulai terjadi gangguan fungsi kedua organ tersebut. Dan hal ini menguntungkan bagi pasien pediatrik yang fungsi organnya masih imatur. Remifentanil adalah salah satu contoh obat tersebut. ${ }^{4}$ Penggunaan remifentanil secara luas pada kasus neuroanestesi pasien dewasa secara tidak langsung mempengaruhi praktek neuroanestesi pasien pediatrik. Remifentanil dapat menimbulkan efek analgesia secara titrasi disertai stabilitas hemodinamik dan memberikan pemulihan yang cepat sehingga dapat dilakukan evaluasi neurologis secara dini dimana hal ini adalah tujuan utama yang ingin dicapai dibidang neuroanestesi. $^{5}$ Remifentanil infus $0,05-0,1$ $\mathrm{mcg} / \mathrm{kgbb} / \mathrm{mnt}$ dengan dosis bolus $1 \mathrm{mcg} / \mathrm{kgbb} /$ iv memberikan analgesia yang efektif dan mempertahankan stabilitas hemodinamik. Durasi yang pendek memberikan pemulihan yang cepat dengan waktu ekstubasi berkisar antara 8-13 menit. $^{6}$

\section{Kasus}

Seorang bayi laki-laki, 7 bulan, BB $7 \mathrm{~kg}$ dengan keluhan benjolan di daerah pantat yang mulai terlihat sejak usia 4 hari. Benjolan semakin lama semakin membesar dan teraba lunak. Visite preoperatif: pasien tampak aktif, tidak ada keluhan demam ataupun batuk dan pilek. Menyusu dengan ASI, tidak ada riwayat tersedak atau kebiruan saat menyusu. Tidak ada riwayat kejang atau penurunan kesadaran atau gangguan neurologis. Riwayat kelahiran: lahir spontan di bidan dengan BBL 4000 gram, langsung menangis. Tidak ditemukan kelainan anus, kelainan jantung, fistel trakeoesofagus, kelainan ginjal dan kelainan ekstremitas lainnya.

\section{Pemeriksaan Fisik}

B1: jalan napas bebas, napas spontan, frekuensi napas 28-34x semenit, auskultasi vesikuler $+/+$, tidak ada ronki dan wheezing. $\mathrm{SpO}_{2} 99-100 \%$ dengan udara bebas (room air); B2: Laju denyut jantung $120 \mathrm{x} /$ menit, S1-S2 tunggal, murmur (-); B3: PGCS 15, pupil isokor, refleks cahaya +/+; B4: Berkemih spontan; B5: abdomen datar, soufle, tidak teraba massa. Perkusi timpani. Auskultasi bising usus normal; B6: kedua akral hangat, suhu tubuh $36^{\circ} \mathrm{C}$.

Status lokalis: tampak massa sebesar bola takraw di sacrum dengan permukaan kulit kemerahan. 
Konsistensi lunak dan tidak ada nyeri tekan.

\section{Hasil Laboratorium}

$\mathrm{Hb}: 13.1 \mathrm{gr} / \mathrm{dL}$; leukosit: 13.100/mm3; hematokrit 38.8\%; trombosit: $518.000 / \mathrm{mm} 3$

PT 10'/aPTT 28.2'/INR 0.90; ureum: 11/Kreatinin 0.41; GDS 92 gr/dL; SGOT 28 IU/SGPT 13 IU.

Thoraks foto: jantung dan paru dalam batas normal; Ct-scan kepala: kesan gangguan perkembangan otak.

Ct-scan lumbosacral: tampak meningokel yang keluar dari defek vertebra lumbal (VL) 4, ukuran $10.3 \times 8.4 \times 11 \mathrm{~cm}$. tampak spina bifida VL4-5.

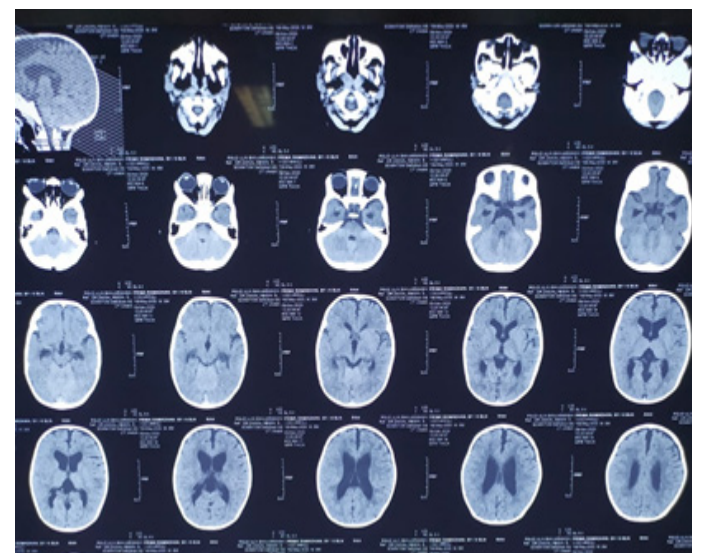

Gambar 1. Ct scan Kepala

Diagnosis: ASA 2 dengan meningokel regio sacral. Rencana tindakan: eksisi meningokel

\section{Intraoperatif}

Pasien datang ke ruang persiapan anestesi sudah terpasang infus $\mathrm{NaCl} 0,9 \%$. Di meja operasi diberikan matras penghangat, dilakukan
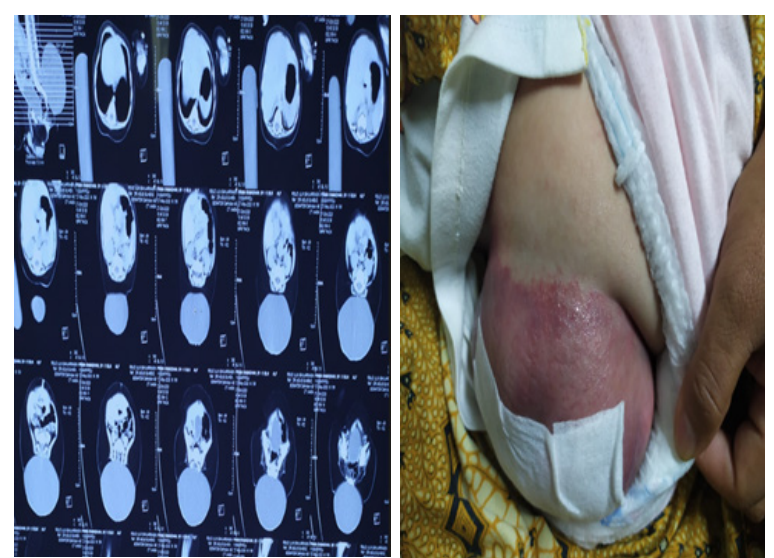

Gambar 2. Ct scan Lumbosacral dan Meningokel pemasangan monitor EKG, pulse oksimetri, suhu dan tensimeter non invasif, serta pemasangan foley kateter. Pasang padding berupa kain yang dibentuk menjadi lingkaran di area meningokel untuk mencegah penekanan dan menghindari terjadinya ruptur. Keempat ekstremitas dibalut dengan softband untuk pencegahan hipotermi. Setelah persiapan selesai dan infus dipastikan lancar, dilakukan pemberian remifentanil $1 \mathrm{mcg} /$ kgbb/iv selama satu menit dilanjutkan dengan remifentanil kontinyus $0,05-0,1 \mathrm{mcg} / \mathrm{kbgg} / \mathrm{mnt}$. Induksi dengan propofol dosis $2,5 \mathrm{mg} / \mathrm{kgbb} / \mathrm{iv}$ sembari melakukan preoksigenasi. Setelah jalan napas dan ventilasi dapat dilakukan dengan baik, diberikan pelumpuh otot dengan atracurium $0,5 \mathrm{mg} / \mathrm{kgbb} / \mathrm{iv}$. Ditunggu hingga 5 menit dan dilakukan intubasi dengan pipa endotrakeal 3,5 cuff. Dilakukan fiksasi ett dan pemasangan tampon orofaring serta plester mata untuk persiapan posisi prone. Rumatan anestesi dengan sevoflurane 1,5-2 vol\%, $\mathrm{FiO}_{2} 60 \% 4 \mathrm{lpm}$ dan remifentanil kontinyu $0,05-0,1 \mathrm{mcg} / \mathrm{kgbb} /$ menit.

Operasi berlangsung selama 2 jam dan lama anestesi 3 jam 20 menit. Saat operasi, operator mengeluarkan cairan likuor dari meningokel sebanyak sekitar $350 \mathrm{cc}$ untuk mempermudah proses operasi. Intraoperatif dilakukan pengecekan gula darah dan diperoleh hasil 192 gr/dL. Jumlah cairan masuk sekitar $100 \mathrm{cc}$ dan transfusi PRC $30 \mathrm{cc}$. Perdarahan selama operasi sekitar $70 \mathrm{cc}$ dan produksi urin selama operasi $50 \mathrm{cc}$. Selama prosedur operasi tidak ditemukan episode bradikardi. Selesai operasi pasien diposisikan supine dan dilakukan ekstubasi setelah

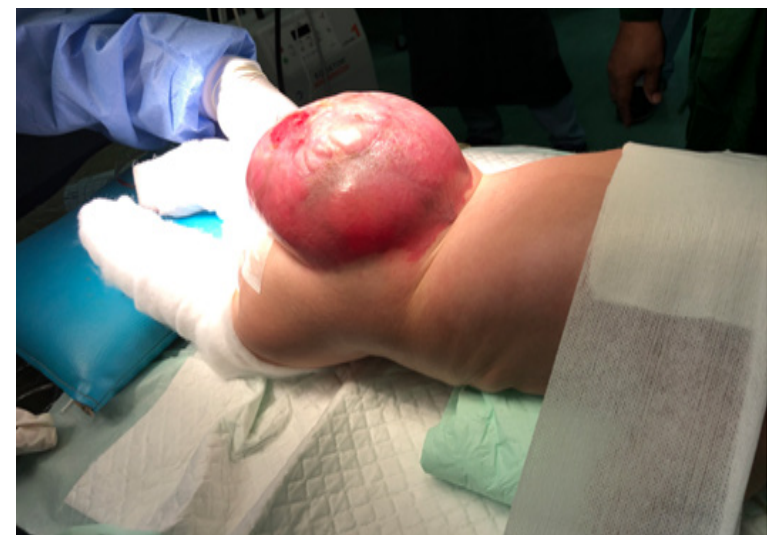

Gambar 3. Pasien dalam Posisi Prone 


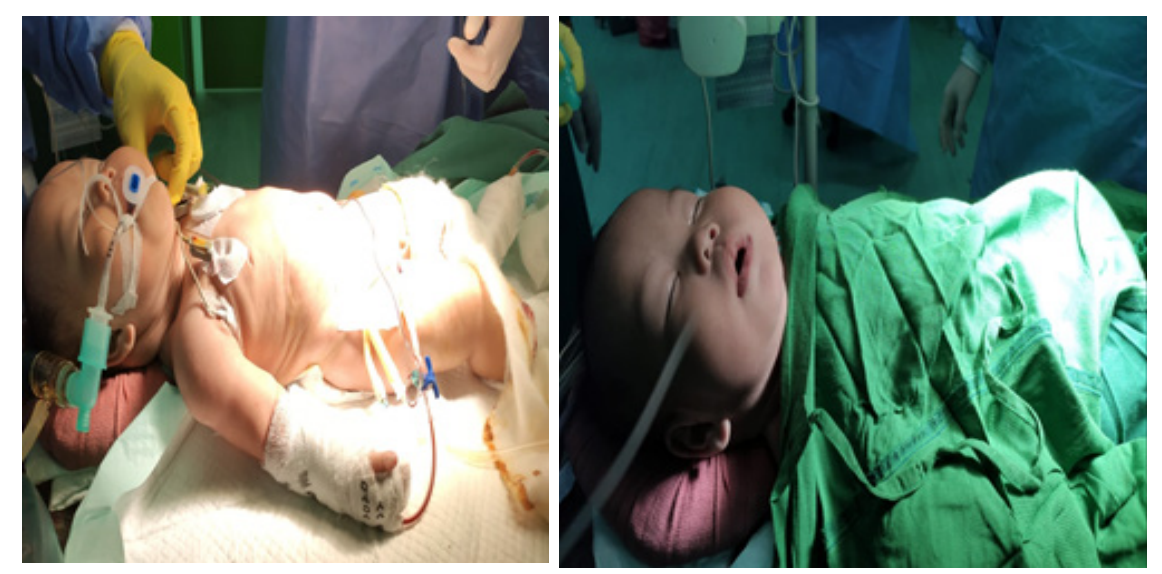

Gambar 5. Kondisi Ekstubasi dan Post-Ekstubasi

napas spontan adekuat dan refleks batuk pulih, untuk menghindari terjadinya laryngospasme. Analgetik postoperasi yang diberikan adalah metamizole $100 \mathrm{mg} /$ iv bolus. Setelah observasi di ruang pemulihan pasien dipindahkan langsung ke ruang perawatan.

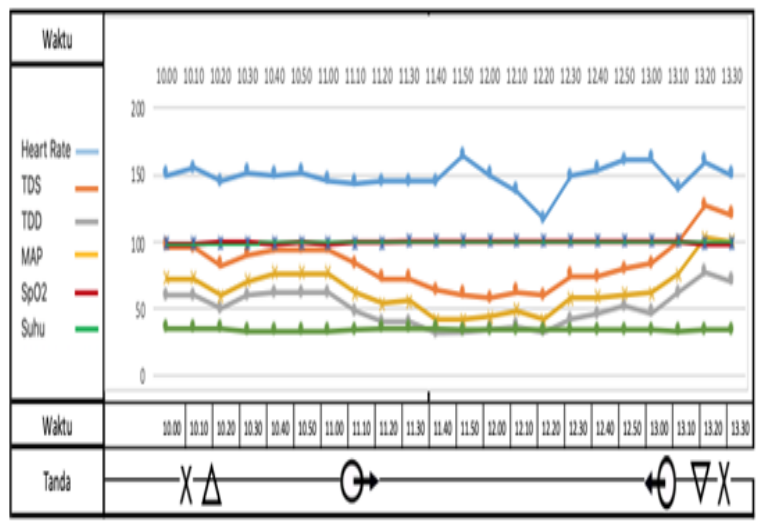

Grafik 1. Observasi Tanda Vital selama Operasi

\section{Pembahasan}

Kegagalan penutupan selubung pipa neural dalam trimester pertama kehamilan akan menyebabkan terjadinya spina bifida hingga anensefali. Kondisi yang umumnya memerlukan koreksi dengan cara operasi adalah meningokel lumbosakral akibat herniasi posterior selubung saraf, dan jika melibatkan jaringan saraf (mielomeningokel) biasanya fungsi neurologis bagian distal akan sangat tergnggu. Defek ini harus langsung dikoreksi dalam beberapa hari setelah bayi lahir untuk meminimalkan kontaminasi bakteri dan sepsis. ${ }^{1,7}$ Meningokel adalah bentuk yang lebih ringan dimana hanya meningen dan jaringan saraf non fungsional yang masuk ke dalam defek. ${ }^{8}$ Kasus ini termasuk terlambat karena pasien datang pada saat usia 7 bulan dengan meningokel yang besar di area lumbosacral. Keuntungannya adalah kondisi meningokel belum pecah, sehingga tidak terjadi kontaminasi bakteri. Tidak dilacak lebih jauh faktor resiko terjadinya meningokel pada kasus ini.

Beberapa faktor resiko terjadinya defek pada selubung saraf spinalis diantaranya adalah ibu yang terpapar teratogen (metotreksat, asam valprota dan aminopterin), ibu dengan diabetes, hipertemia, status sosial ekonomi yang rendah, defisiensi asam folat dan kelainan genetik. Janin dengan gangguan ini dapat menyebabkan abortus spontan, lahir hidup, kematian diawal kehidupan atau hidup dalam kondisi cacat seumur hidup. ${ }^{9}$ Implikasi anestesi pada operasi penutupan defek selubung saraf ini adalah 1) jika operasi dilakukan pada neonatus: lakukan prinsip umum anestesi pada neonatus. Jika diperlukan skin graft, persiapkan pergantian darah; 2) posisi: berikan tekanan minimal pada struktur kistik untuk mencegah terjadinya kerusakan atau ruptur, Induksi anestesi dapat dilakukan dalam posisi lateral decubitus atau supine beralaskan busa berbentuk cincin untuk mengurangi penekanan pada defek area. Operasi dilakukan dalam posisi prone dan mencegah kompresi pada bagian abdomen dan kongesti vena pada area operasi; 3) lateks: pasien pediatrik dengan mielodisplasia memiliki faktor resiko tinggi terjadinya alergi lateks. ${ }^{3,7}$ 
Operasi spinal adalah prosedur mayor pada pasien pediatrik dengan problem medis, sehingga perlu dilakukan investigasi preoperatif. Lesi mielodisplasia saraf pusat biasanya tidak dikaitkan dengan adanya anomali kongenital organ lain, khususnya kelainan jantung kongenital sehingga saat dilakukan skrining preoperative tidak meliputi evaluasi kardiologi. Defek vertebra dikaitkan dengan anomali kongenital lainnya. Sindrom VACTERL: defek vertebra, malformasi anorektal, anomali kardiovaskuler, fistel trakeoesofagus, renal (genitourinaria) dan malformasi ekstremitas ditemukan pada 13\% pasien pediatrik dengan fistel trakeoseofagus. ${ }^{1}$ Pada kasus ini tidak ditemukan kelainan VACTERL lainnya. Induksi anestesi dilakukan dengan menghindari terjadinya kenaikan tekanan intrakranial (TIK) akibat hiperkapnia, hipoksia, variasi tekanan arteri rerata (mean arterial pressure $=\mathrm{MAP})$ dan efek agen inhalasi yang meningkatkan aliran darah otak (ADO). Induksi intravena dengan propofol atau thiopental dan pelumpuh otot non depolarisasi ideal untuk dilakukan. ${ }^{7}$ Pada kasus ini pasien sudah dalam kondisi terpasang infus, dengan adanya akses vena dilakukan induksi secara intravena dengan menggunakan propofol.

Pada pasien yang belum terpasang akses intravena atau mengalami kesulitan dalam memasang iv kanula, dapat dilakukan induksi dengan gas inhalasi untuk menghindari kenaikan TIK akibat menangis atau melawan saat pasien akan dipasang jalur infus. Sevofluran dapat digunakan karena baunya yang enak, dan tidak mengiritasi jalan napas sehingga menghindari terjadinya laringospasme dan menahan napas (breath holding). Jika akan dilakukan induksi secara cepat (rapid sequence induction), terjadinya kenaikan TIK akibat pemberian suksinil kolin dapat dihindari dengan penggunaan opiat atau memberikan dosis defasikulasi dengan pelumpuh otot nondepolarisasi sebelum penyuntikan suksinil kolin. Opiat seperti remifentanil atau alfentanil harus diberikan untuk mengurangi respon hipertensi akibat laringoskopi, intubasi dan operasi. ${ }^{7}$ Pada saat pasien diposisikan prone, perlu dipastikan pipa endorakeal terfiksasi baik sebelum membalik pasien. Proteksi mata dan pressure point harus betul-betul diperhatikan. Melakukan posisi dengan hati-hati menjadi hal utama untuk menghindari terjadinya komplikasi seperti dislokasi atau kinking pipa endotrakea, abrasi kornea atau neuropati perioperatif. Kepala biasanya diletakkan pada headrest dalam posisi netral atau miring kesatu sisi di atas bantal. Hal ini utamanya adalah untuk membuat abdomen bebas dan mudah diventilasi, tapi juga mengurangi kehilangan darah dengan cara mencegah kompresi vena cava inferior dan meningkatkan kompresi vena paraspinal. ${ }^{1,3}$ Rumatan anestesi dapat menggunakan agen inhalasi atau total intravenous anesthesia (TIVA) dengan kombinasi opiat kerja singkat dan ventilasi terkontrol Pada pasien pediatrik TIVA dapat digunakan, tapi pada pasien dengan usia lebih muda penggunaan TIVA masih terbatas dengan adanya retriksi berat badan pada alat target controlled infusion (TCI). Agen inhalasi dengan konsentrasi 1 minimum alveolar concentration (MAC) tidak dikaitkan dengan kenaikan aliran darah otak (ADO). Halotan merupakan vasodilator otak dan menyebabkan kenaikan ADO yang tergantung dosis. Isofluran mempengaruhi ADO lebih sedikit jika dibandingkan halotan pada MAC yang ekuivalen. Sevofluran dan desflurane memiliki efek fisiologis ke otak yang mirip dengan isoflurane, tetapi memberikan stabilitas hemodinamik yang lebih baik dan pulih sadar yang cepat setelah operasi lama. $^{7}$

Pada kasus ini rumatan anestesi dengan sevoflurane $1,5-2$ vol\% sesuai respon hemodinamik pasien dikombinasikan dengan remifentanil $\quad 0,05-0,1 \quad \mathrm{mcg} / \mathrm{kgbb} / \mathrm{mnt}$ secara kontinyus melalui syringe pump. Fokus selama intraoperatif adalah meminimalkan iskemik dan penekanan medulla spinalis. Hal ini dilakukan dengan cara mempertahankan tekanan perfusi medulla spinalis (spinal cord perfusion pressure = SCPP) melalui kontrol tekanan darah dan meminimalkan kongesti vena dengan cara melakukan posisi prone secara hati-hati untuk mencegah penekanan abdomen. Sehingga perfusi medulla spinalis tetap terjaga dan di lapangan operasi perdarahan minimal. Untuk mencapai tujuan ini penggunaan remifentanil menjadi semakin popular. Remifentanil adalah 
opiat dengan durasi kerja sangat singkat yang memberikan efek analgesi yang memuaskan, onset cepat, sangat baik diberikan secara titrasi dan cepat hilang efeknya. Remifentanil dapat digunakan sebagai bagian dan regimen rumatan dengan agen inhalasi atau intravena. Propofol dan remifentanil dapat digunakan bersamaan untuk TIVA pada pasien pediatrik di atas 15 tahun. ${ }^{1,3,7}$ Pertimbangan utama untuk penggunaan remifentanil adalah perbedaan fisiologi neonatus dan infant dengan orang dewasa, dimana sistem organ vital yang masih imatur membuat safety margin terbatas untuk manajemen perioperatif dan selama tindakan anestesi. Remifentanil memiliki karakteristik yang menguntungkan seperti onset cepat, efek analgesik yang poten dan eliminasi yang cepat. ${ }^{10}$ Remifentanil adalah opiate sintetis 4-anilidopiperidine dengan afinitas yang kuat terhadap reseptor $\mu$ dibandingkan reseptor $\delta$ dan $\kappa$. Remifentanil dikatakan setara atau lebih poten $2 x$ lipat dari fentanyl dan sekitar $1 / 10$ potensi sufentanil meski belum dapat dipastikan ekuivalensinya. Efek remifentanil dapat diantagonis oleh nalokson. ${ }^{6}$

Rapid onset remifentanil dimungkinkan karena waktu yang diperlukan untuk mencapai keseimbangan darah-otak hanya sekitar 1-2 menit. Infus $0,05-0,1 \mathrm{mcg} / \mathrm{kgbb} / \mathrm{mnt}$ memberikan analgesia dengan konsentrasi $1-3 \mathrm{ng} / \mathrm{mL}$ di dalam darah. Eliminasi waktu paruh yang singkat membuat durasi kerja singkat dan pasien akan mengalami pemulihan dalam waktu 5-10 menit setelah penghentian dosis. Cepatnya bersihan obat juga membuat terhindarnya akumulasi obat, berbeda dengan opiat lain hal ini membuat durasi kerja remifentanil tidak meningkat jika obat diberikan dalam waktu lama. ${ }^{6}$ Remifentanil memungkinkan digunakan pada pasien neonatus yang memerlukan operasi. Memberikan keuntungan terutama pada pasien yang ingin diekstubasi segera setelah operasi. ${ }^{10}$ Pada orang dewasa yang dilakukan cardiopulmonary bypass (CPB) dikatakan remifentanil memberikan efek antiinflamasi. Infus remifentanil menekan kenaikan gula darah dan kadar laktat dan berfungsi sebagai vasodilator selama CPB pasien pediatrik. Belum dapat ditentukan dosis optimal infus remifentanil yang mampu mencegah kenaikan kadar gula darah dan kadar laktat selama CPB pada pasien pediatrik. ${ }^{11}$ Pada pasien pediatrik yang dilakukan operasi mata, penggunaan infus remifentanil efektif untuk mencegah terjadinya emergence agitation (EA) tanpa disertai lonjakan hemodinamik atau memperlambat waktu pemulihan dengan sevofluran. Penggunaan infus remifentanil $0,1 \mathrm{mcg} / \mathrm{kgbb} / \mathrm{mnt}$ efektif dalam mengurangi insiden EA pada pasien pediatrik yang menjalani operasi mata dengan sevoflurane. ${ }^{12}$ Seperti opiate lainnya, remifentanil menyebabkan apnea, depresi napas, hipotensi dan bradikardi yang tergantung dosis. Efek puncak terhadap hemodinamik biasanya terjadi dalam 3-5 menit setelah dosis inisial atau jika diberikan dosis tambahan. Efek menurunkan tekana arteri rerata tergantung pada dosis atau konsentrasi obat yang telah dibuktikan pada beberapa penelitian. Rigiditas otot terjadi jika diberikan dosis lebih dari $1 \mathrm{mcg} / \mathrm{kgbb}$ atau laju infus lebih dari 0,1 $\mathrm{mcg} / \mathrm{kgbb} / \mathrm{menit}$. Tetapi penggunaan remifentanil mengurangi penggunaan pelumpuh otot. ${ }^{6}$ Pada kasus ini, tidak terjadi episode bradikardi dengan penggunaan remifentanil secara kontinyus. Pasien dapat dilakukan ekstubasi dengan pengurangan dosis dan remifentanil baru dihentikan setelah pipa endotrakeal dilepas. Pasien tampak tenang dan di ruang pemulihan pasien menangis kencang dan sadar baik seperti sebelum dioperasi.

\section{Simpulan}

Telah dilaporkan satu kasus pasien pediatrik dengan meningokel lumbosacral yang dilakukan eksisi meningokel dalam posisi prone menggunakan remifentanil kontinyus dan sevoflurane. Tidak terjadi episode bradikardi selama operasi, dan pascaoperasi pasien dapat segera diekstubasi. Pilihan penggunaan remifentanil adalah karena fungsi sistem organ pasien pediatrik yang masih imatur dengan safety margin yang terbatas. Remifentanil memberikan onset cepat, efek analgesi poten dan eliminasi yang cepat, sehingga pulih sadar juga menjadi cepat untuk evaluasi fungsi neurologis pasien,

\section{Daftar Pustaka}

1. Soundararajan N, Cunliffe M. Anaesthesia 
for spinal surgery in children. Br J Anaesth. 2007;99(1):86-94.

2. Özek MM, Cinalli G, Maixner WJ. The spina bifida: Management and outcome. Spina Bifida Manag Outcome. 2008;(May 2014):1532.

3. DeCuypere M. Perioperative considerations and positioning for neurosurgical procedures. In: Saliba C, Avramescu S, eds. Anesthesia \& Analgesia. Vol 128. ; 2019:e7.

4. Martin LD, Jimenez N, Lynn AM. A review of perioperative anesthesia and analgesia for infants: Updates and trends to watch. F1000Research. 2017;6(Paris 7).

5. Marsh DF, Hodkinson B. Remifentanil in paediatric anaesthetic practice. Anaesthesia. 2009;64(3):301-08.

6. Buck ML. Pediatric pharmacotherapy. KodaKimble Young's Appl Ther Clin Use Drugs. 2013;19(5):2265-76.

7. Furay C, Howell T. Paediatric neuroanaesthesia. Contin Educ Anaesthesia,
Crit Care Pain. 2010;10(6):172-176.

8. Mautes AEM, Noble LJ. Injury : Contribution to Secondary. 2000;80(7):673-687.

9. Seidahmed MZ, Abdelbasit OB, Shaheed, MM, Alhussein KA, Miqdad AM, Khalil MI, et al. Epidemiology of neural tube defects. Saudi Med J. 2014;35:S29-S35.

10. Soontrakom T, Kamata M, Kuratani N. Use of remifentanil in general anesthesia for neonatal non-cardiac surgery: a case series. JA Clin Reports. 2018;4(1):6-9.

11. Chaki T, Nawa Y, Tamashiro K, Mizuno E, Hirata N, Yamakage M. Remifentanil prevents increases of blood glucose and lactate levels during cardiopulmonary bypass in pediatric cardiac surgery. Ann Card Anaesth. 2017;20(1):33-37.

12. Choi YH, Kim KM, Lee SK, Kim YS, Kim SJ, Hwang WS, et al. Effects of remifentanil and remifentanil-alfentanil administration on emergence agitation after brief ophthalmic surgery in children. BMC Anesthesiol. 2016;16(1):1-7. 